\title{
Impact of direct-acting antiviral agents on the development of hepatocellular carcinoma: evidence and pathophysiological issues
}

\author{
Maria Tampaki ${ }^{a}$, Spiros Savvanis ${ }^{b}$, John Koskinas ${ }^{a}$ \\ Medical School, National and Kapodistrian University of Athens, "Hippokration" General Hospital; General Hospital \\ "Elpis", Athens, Greece
}

\section{Abstract}

\section{Introduction}

Chronic infection with hepatitis $\mathrm{C}$ virus (HCV) affects more than 70 million individuals worldwide [1]. Progression of liver disease to advanced fibrosis or cirrhosis due to chronic HCV infection is a risk factor for the development of hepatocellular carcinoma (HCC), with an annual rate ranging from 1-7\% [2]. The prognosis of HCC remains poor, because it has usually reached an advanced stage by the time of diagnosis. HCC is considered as the third leading cause of cancer death in the world and it is estimated to be responsible for approximately 1 million deaths per year [3].

$\mathrm{HCV}$ incidence has shown a declining trend in recent years. This is mainly due to decreased exposure to HCVrelated risk factors, which include injected drug use and

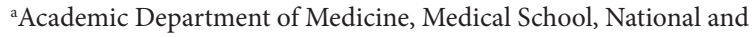
Kapodistrian University of Athens, "Hippokration" General Hospital (Maria Tampaki, John Koskinas); 'Department of Internal Medicine, General Hospital "Elpis" (Spiros Savvanis), Athens, Greece
\end{abstract}

Conflict of Interest: None

Correspondence to: John Koskinas, MD, PhD, 118 Vasilissis Sofias, 11521 Athens, Greece, e-mail: koskinasj@yahoo.gr

Received 22 June 2018; accepted 20 July 2018; published online 14 September 2018

DOI: https://doi.org/10.20524/aog.2018.0306 contaminated blood product transfusion [4]. This declining course was interrupted by a rise of HCV incidence among people who inject drugs [5]. On the other hand, we are now in the era of interferon (IFN)-free anti-HCV treatments, since the development of many very potent direct-acting antiviral agents (DAAs), which provide impressively high rates (>95\%) of sustained virological response (SVR) [6].

The expected wide use of this new generation of antiviral treatments makes it difficult to predict the incidence of HCVrelated cancer in the future. The prediction is even more difficult since other morbidities such as non-alcoholic fatty liver disease or non-alcoholic steatohepatitis, obesity, and diabetes are on the increase as independent risk factors for the development of HCC [7]. Moreover, it must be taken into consideration that there is a long interval, 2-8 decades, from the initial HCV infection to the development of HCC [8]. During this long period, many pathological processes take place, including chronic inflammation, hepatocyte death, regeneration, fibrosis, and cirrhosis [9]. Nowadays, the residual damage and its surveillance after the successful treatment of chronic HCV infection are not the only issues. There are also some concerns about the role of DAAs in the recurrence or development of HCC after the achievement of a virological response.

The aim of this article is to review published data on the risk of HCC occurrence or recurrence following DAA therapy and provide a literature update on the underlying immunological mechanisms. 


\section{The impact of IFN treatments on HCC occurrence}

According to previous studies focusing on the effects of IFN treatment, the eradication of HCV reduces the longterm incidence of HCC while halting the progression of disease, thus preventing the clinical complications associated with chronic viral infection [10,11]. In 1995 Nishiguchi et al.[12] showed that patients with HCV-related cirrhosis who achieved SVR with IFN treatment had a lower risk of HCC development. Since then, other studies with long-term follow up, such as the HALT-C trial (Hepatitis C Antiviral Long-term Treatment against Cirrhosis) [13], the CO-PILOT (Colchicine versus Peginterferon alfa $2 \mathrm{~b}$ Long-term Therapy) [14], the EPIC3 (Evaluation of PegIntron in Control of Hepatitis C Cirrhosis) $[15,16]$, and a trial by the Swedish Hepatitis Group [17], have confirmed that patients who achieved SVR had a lower incidence of HCC compared to non-responders. However, patients older than 65 years old and those with advanced liver fibrosis or cirrhosis are at higher risk [18]. The long-term risk of developing HCC persists in cirrhotic patients for up to 8-10 years, especially in the presence of comorbidities such as diabetes $[17,19]$.

\section{The impact of DAAs on HCC de novo occurrence and recurrence}

In the era of IFN-free regimens, $\mathrm{HCV}$ patients can receive treatment regardless of HCV genotype, fibrosis stage or even the presence of severe comorbidities [20]. However, concerns were raised when two studies reported both increased rates of de novo HCC occurrence and unexpectedly high rates of recurrence in patients who cleared HCV after IFN-free DAA therapy $[21,22]$. Conti et al. in a retrospective cohort study from Italy, observed a significant increase $(28.81 \%)$ in the early recurrence of HCC in $59 \mathrm{HCV}$ patients who had SVR after DAA treatment and had been previously treated for HCC, either with curative regimens (resection and radiofrequency ablation) or with potentially non-curative treatment (transcatheter arterial chemoembolization [TACE]) [21]. Moreover, Reig et al.investigated the benefits of DAAs in a cohort of 58 patients with a prior history of HCC and complete response to heterogeneous types of treatment, such as resection, ablation or chemoembolization. After a median follow up of 5.7 months, 16 of 58 (28\%) patients exhibited HCC recurrence [22].

Since then, several studies have been conducted with a view to reevaluating the role of DAAs and the established general assumption that HCV eradication minimizes the risk of HCC development. The ANRS collaborative study group on HCC elaborated the results of 3 prospective multicenter cohort studies in France (ANRS CO22 HEPATHER, CO12 CIRVIR, and CO23 CUPILT). This analysis, which included more than 6000 patients treated with DAAs, did not support an increased risk of HCC recurrence after DAA therapy [23]. However, in contrast to both previous studies, the ANRS register enrolled only HCC patients treated with curative procedures, including patients who received orthotopic liver transplantation (OLT), but excluded HCC patients treated with TACE [23].

Yang et al.investigated pre- and post-OLT outcomes in patients with HCV-associated HCC treated with DAAs and compared them to those of untreated patients. Unexpectedly, a trend toward a higher risk of HCC recurrence was reported in patients who had received pre-OLT DAA treatment $(5 / 18$, $27.8 \%)$ compared to the risk in untreated patients $(6 / 63$, 9.5\%) [24]. Nevertheless, it should be taken into account that most of the studies showing an increased risk for HCC recurrence (Table 1) were retrospective and included relatively small numbers of patients with quite heterogeneous characteristics. Two recent prospective studies by Cabibbo et al.and Kassas et al.[26,30], which included a relatively small number of patients, yielded conflicting results and cannot provide a clear conclusion. Based on the above, large, prospective cohorts with adequately homogeneous patient populations, in terms of HCC staging system, treatment strategy and evaluation of HCC response before DAA administration, are needed.

Apart from the reports of higher HCC recurrence rates, a higher rate of de novo HCC appearance has also been described. In a report from a single US tertiary center, 9 of $66 \mathrm{HCV}$ cirrhotic patients who received DAAs developed de novo HCC over a period of 6 months following the end of therapy [31]. The same trend appeared in patients with negative history for HCC who showed de novo occurrence (9 of 285 patients; $3.16 \%$ ) during a follow-up period of 24 weeks after DAA therapy in the abovementioned study by Conti [21].

On the other hand, a recent retrospective analysis of 22,500 DAA-treated HCV patients from a US Veteran Cohort has shown that, compared to patients without SVR, those with SVR had a significantly lower risk of HCC (0.90 vs. $3.45 \mathrm{HCC} / 100$ patient years; adjusted hazard ratio, 0.28, 95\% confidence interval 0.22-0.36). However, in the same analysis, cirrhotic patients who achieved SVR had higher HCC rates compared to the general population [32]. The most recent study by Ioannou et al.further supports the opinion that DAA-induced SVR is not associated with an increased risk for HCC. According to a retrospective analysis of 62,354 patients who received anti-HCV treatment from 1999 to 2015 (IFN, IFN+DAAs, or DAAs only), the achievement of SVR led to a significant reduction in HCC development, regardless of the type of regimen. More specifically, DAA-induced SVR resulted in a $71 \%$ reduction in HCC risk [33]. In summary, in terms of DAA-related de novo HCC occurrence, all retrospective studies [32,33,36,37,39] investigating this hypothesis, apart from 2 smaller studies by Ravi et al.and Conti et al.[21,31] (Table 2), as well as two recent large, prospective cohorts by Calvaruso et al.and Romano et al.[34,35], clearly show that there is no increased risk of HCC following HCV eradication with DAA regimens. Furthermore, SVR seems to have a protective effect against HCC development, regardless of the type of antiviral treatment.

Although there is no convincing explanation for the reported "better" outcomes in IFN-containing regimens, we should emphasize the obvious bias that characterizes studies focusing on DAA treatment, since HCV patients with severely 


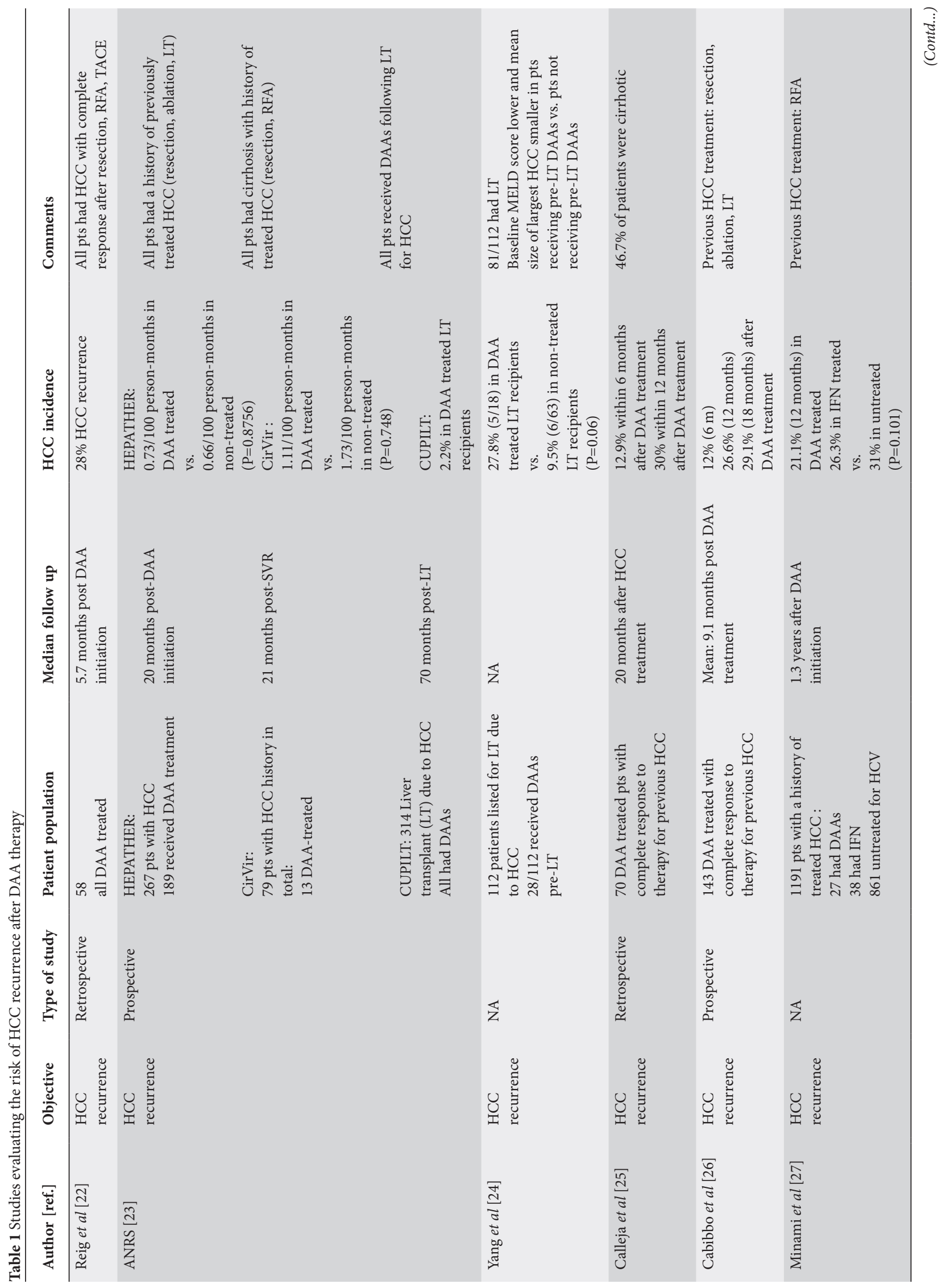




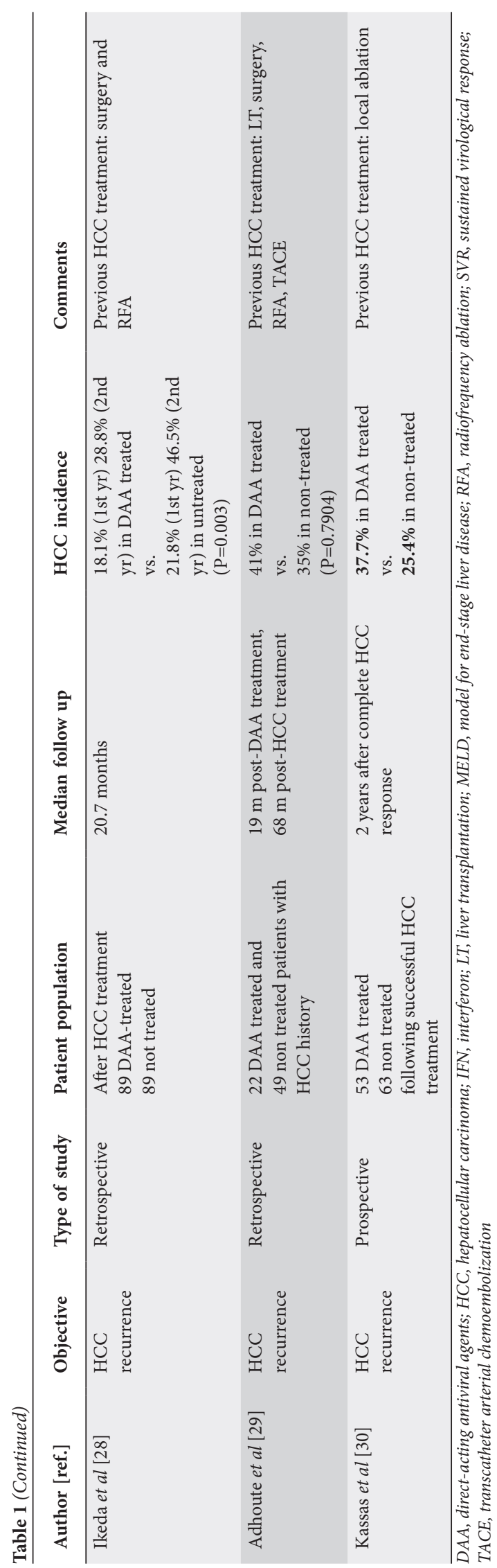

impaired liver function or other significant comorbidities who received DAAs would not have been qualified to receive IFN treatment.

The clinical impact of HCV eradication is more relevant in patients with compensated cirrhosis, who have not developed clinically significant portal hypertension, liver decompensation or HCC $[10,11]$. HCV eradication leads to elimination of the inflammatory status and the subsequent up-modulation of liver regeneration, which could lead to a progression of precancerous lesions into malignant cell clones [40,41]. Experimental studies have shown that the oxidative damage induced by chronic inflammatory status causes DNA double-strand breaks (DSBs), leading to cell cycle arrest, DNA repair and apoptosis [42,43]. Under the replicative stress following the elimination of $\mathrm{HCV}$, some of the impaired cells containing DSBs could reenter the replicative cycle with increased genomic instability, thus facilitating tumorigenesis [42]. Similar scenarios have been postulated in patients who had surgery for HCC. It has been suggested that, considering the stress after ischemia reperfusion, the subsequent liver regeneration promotes acceleration of liver tumor growth or even carcinogenesis after resection [44].

\section{The role of the immune system}

IFN treatment for $\mathrm{HCV}$ is based on anti-inflammatory and immunomodulatory mechanisms that inhibit viral replication, leading to virus elimination in a substantial number of patients [45]. The possible alterations in the immune system after clearance of the virus with the DAAs and how they may affect the conventional cancer immunity cycle are still unknown.

\section{HCV-related T-cell exhaustion}

In chronic $\mathrm{HCV}$ infection, the continuous antigen stimulation and the impaired $\mathrm{CD}^{+} \mathrm{T}$ cells can lead to exhaustion and/or deletion of pathogen-specific $\mathrm{CD}^{+} \mathrm{T}$-cell clones [46]. This leads to a loss of immune control during chronic infection. Initially, the effector $\mathrm{T}$ cells lose their proliferative capacity and fail to develop into memory $\mathrm{CD}^{+}$ $\mathrm{T}$ cells. Subsequently, they present with impaired cytokine production and ultimately low IFN $\gamma$ production [47]. The "exhausted" T cells are a heterogeneous population of virusspecific CD8 $\mathrm{T}$ cells that go through a maturation process $[48,49]$. At least two distinct virus-specific CD8 T-cell subpopulations are included, the T-bet ${ }^{\text {hi }} \mathrm{PD}-1^{\text {int }} \mathrm{CD} 8 \mathrm{~T}$ cells, representing the progenitor cells that increase in response to persisting antigen stimulation, leading to progressive differentiation to the Eomes ${ }^{\text {hi }} \mathrm{PD}-\mathrm{1}^{\text {hi }} \mathrm{CD} 8 \mathrm{~T}$ cells, the terminal progeny, which do not have replicative ability and persist over the long-term during a chronic infection (Fig. 1) [50]. This phenomenon of antigen stimulation, required for their continued survival, is referred as antigen addiction $[49,50]$. At the more advanced stages, the above process leads to a markedly diminished number of progenitor cells compared 


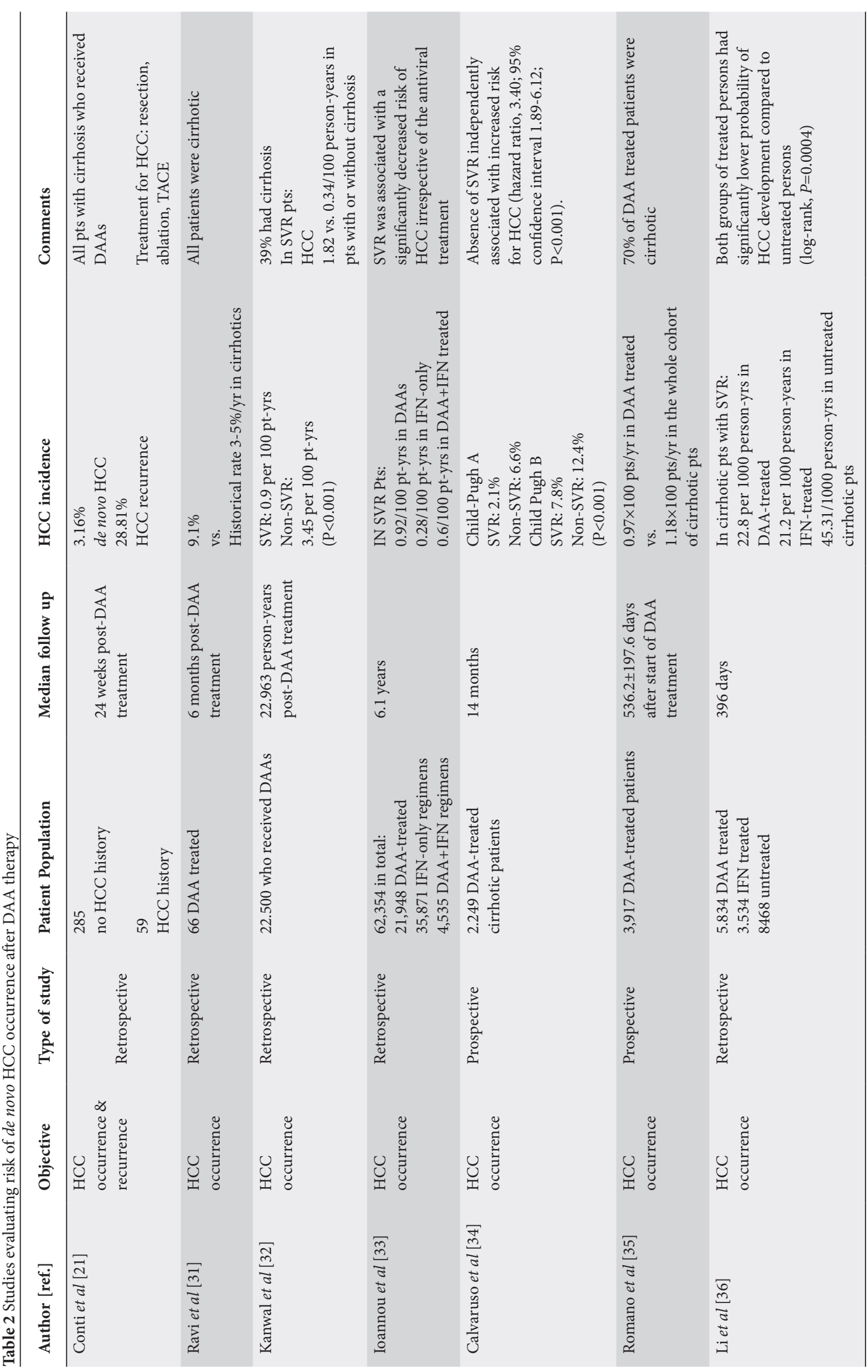




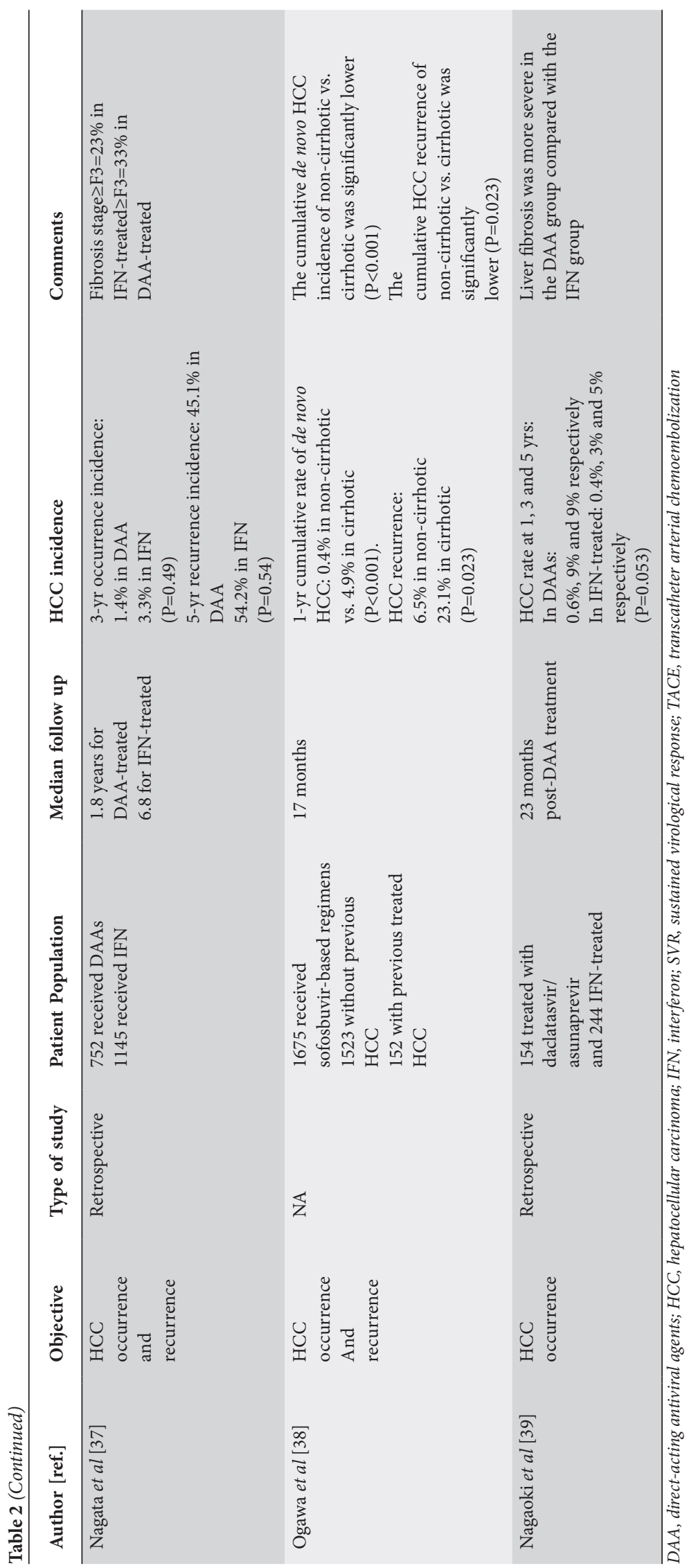


to the terminally differentiated $\mathrm{T}$ cells, a situation that may lead to a loss of immune control in chronic infections [48]. Characteristically, in their differentiation process, they express high levels of numerous inhibitory receptors (PD-1, LAG3, CD160, 2B4, TIM-3, CTLA-4). However, the blockade of PD-1 can induce specific "revitalization" of the T-bet ${ }^{\text {hipD- }}$ $1^{\text {int }} \mathrm{CD} 8 \mathrm{~T}$ cells [51]. All the above indicate the complexity of the mechanisms that lead gradually to CD8 T-cell exhaustion during chronic infection, while it is still unknown whether or how current treatments could reverse the process.

\section{HCV-related dysfunctional CD4 T cell response}

Patients with chronic hepatitis develop a lack of effective CD4 responses combined with a progressive expansion of regulatory T cells (Treg) (Fig. 1) and a reduction in interleukin (IL)-17-expressing T cells (Th17 cells) [52]. This change in the Treg/Th17 ratio leads to an impaired capability to eliminate the $\mathrm{HCV}$ virus, due to the suppression of $\mathrm{HCV}$-specific $\mathrm{CD}^{+}$ $\mathrm{T}$ cells through increased IL-10 production [53]. Moreover, the affected balance between Treg and Th17 cells could generally impact the process and outcome of autoimmune and inflammatory pathways [53], including immunological defense versus development of malignancy.

\section{The impact of HCV treatment on immune response}

IFN treatment has been shown to partially reinforce the recovery of the impaired immune response, resulting in a post-treatment decline in circulating and liver-infiltrating
Treg cells [54]. In this context, it should be noted that the slower kinetics of virus elimination, in parallel with the immune modulatory and anti-proliferative properties of IFN, could contribute to a more gradual restoration of post-SVR immune function [55]. In contrast, there is the hypothesis that swift HCV eradication with DAAs could have a presumably destabilizing effect on the immune reconstitution in the liver microenvironment, caused by rapid reduction of viral load and leading to impaired surveillance of HCC occurrence or recurrence [55]. A recent study by Langhans et al examined the levels of Tregs before therapy and at different time points during and after successful treatment with sofosbuvir plus IFN, or with IFN-free regimens [56]. The population of Tregs, increased at baseline because of chronic HCV infection, did not normalize regardless of treatment type, while the Tregs activation status remained high even 1 year after successful treatment. Based on this observation, all DAA treatments, including those combined with IFN, failed to restore Treg activity to normal levels following HCV elimination [56]. Persistence of negative modulation by Treg cells may negatively contribute to immune reconstitution, even long after HCV has been cured, with an unknown impact on the process of carcinogenesis.

Nevertheless, according to Serti et al [57], successful HCV clearance with DAAs can rectify abnormal natural killer (NK)-cell activity due to chronic HCV infection. Specifically, it has been reported that antiviral treatment with daclatasvir/ asunaprevir caused the normalization of NK-cell cytotoxic effector functions by altering the type of cytokine production as soon as the second week of treatment (Fig. 2). As a result, suppressed production of IFN $\gamma$ and tumor necrosis factor- $\alpha$ by NK cells returned to normal, while the number of cytotoxic CD107 NK cells decreased. In total, these alterations following DAA treatment represent the reset of NK cells to their original phenotype and activity as observed before chronic $\mathrm{HCV}$

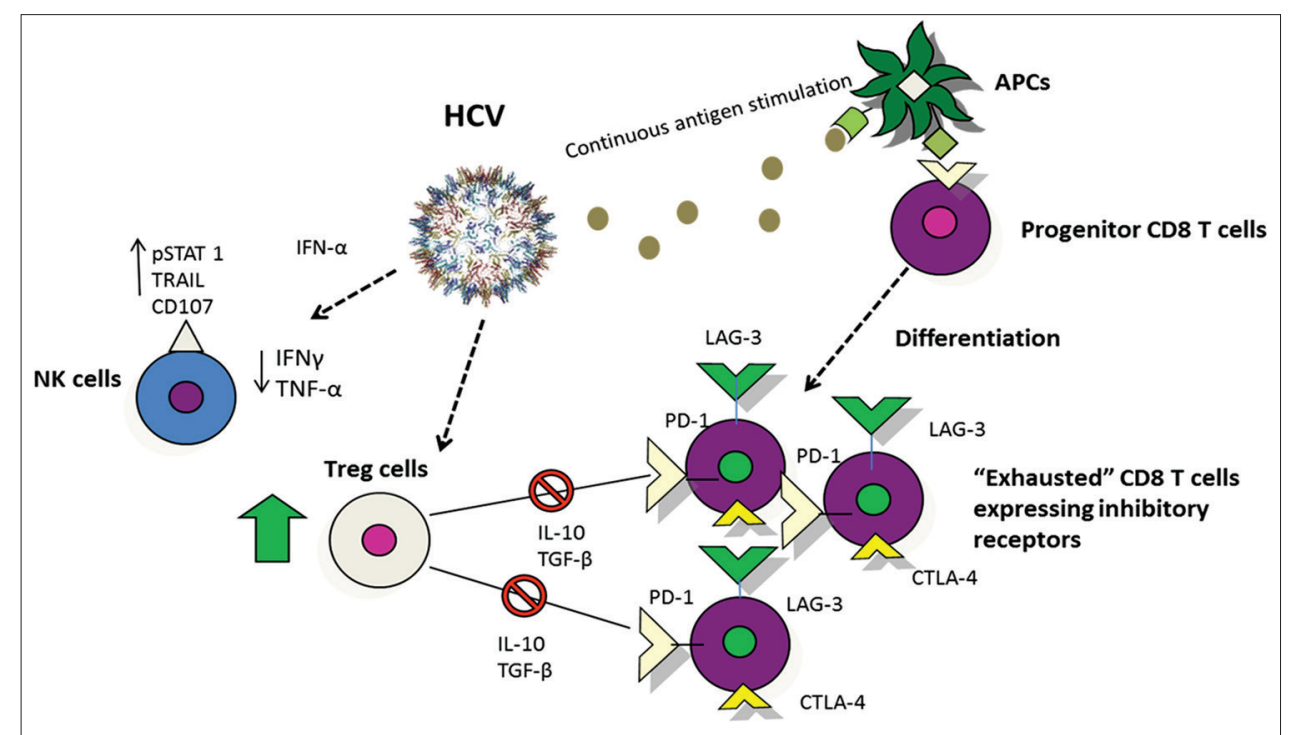

Figure 1 Immunological effects of chronic hepatitis $\mathrm{C}$ virus (HCV) infection: NK cells show abnormal activity with suppressed cytokine production, CD8 T-cell exhaustion expressing mainly inhibitory receptors, and increased Treg cells causing suppression of HCV-specific CD8 T cells HCV, hepatitis C virus; NK cells, natural killer cells; Treg, regulatory; T cells TNF- $a$, tumor necrosis factor alpha; IL-10, interleukin-10; TGF- $\beta$, transforming growth factor beta; IFN- $\gamma$, interferon gamma; APCs, antigen presenting cells 


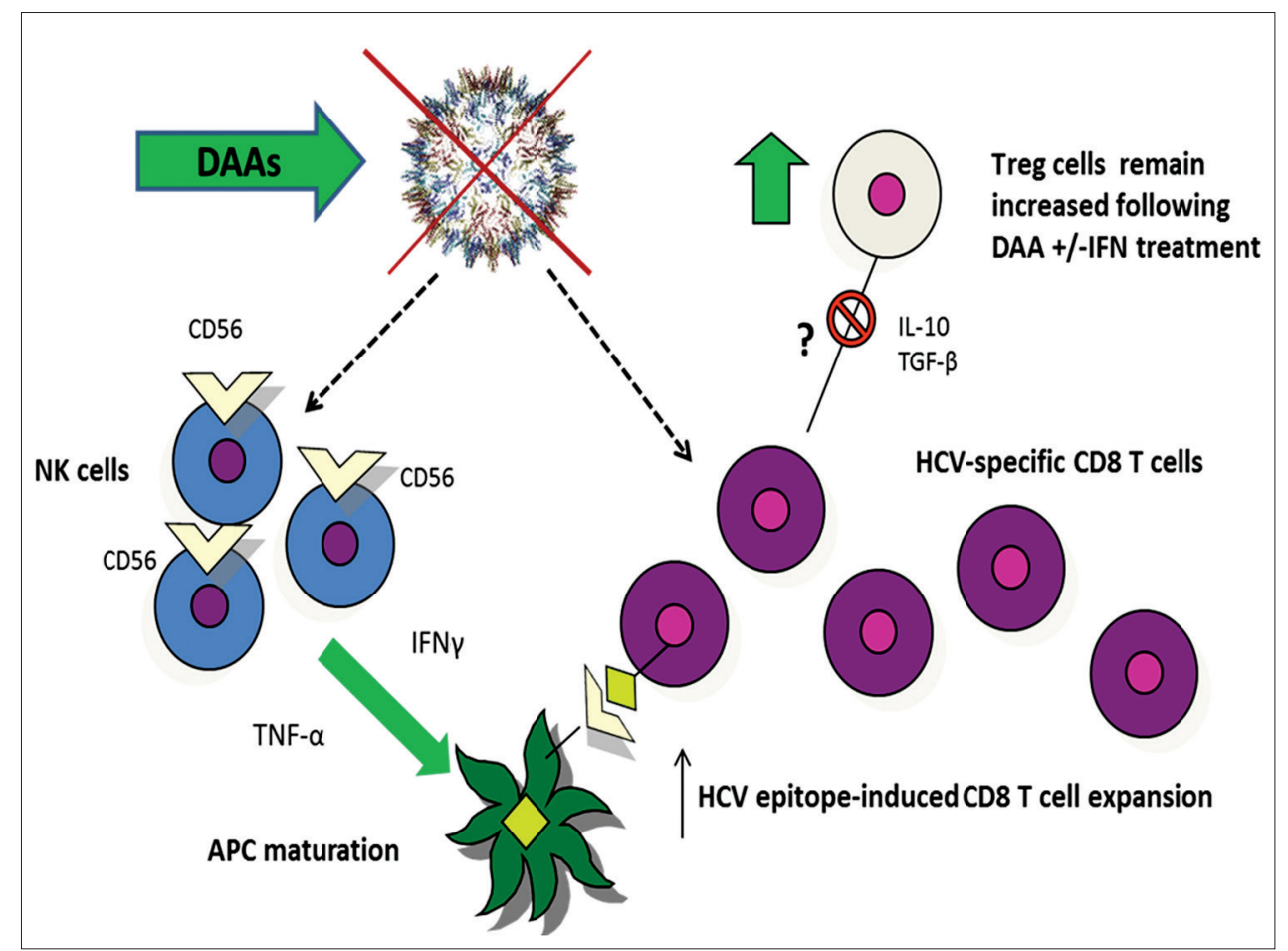

Figure 2 Impact of DAA-induced HCV clearance on immune functions: restoration of NK cell activity with increased IFN $\gamma$ and TNF- $\alpha$ production, leading to APC maturation and proliferation of HCV-specific CD8 T cells. No impact on Treg population is seen following DAA treatment + /- interferon

APC, antigen-presenting cell; DAAs, direct-acting antiviral agents; HCV, hepatitis C virus; IFN, interferon; IL, interleukin; TGF, transforming growth factor; Treg, regulatory T cells; TNF-a, tumor necrosis factor alpha

infection [57]. This is further supported by a recent study specifically showing an increased frequency of CD56 NK cells in the peripheral blood of $31 \mathrm{HCV}$ patients at the end of treatment and following achievement of SVR with DAAs [58]. The observed normalization of innate immune activity after successful DAA treatment could contribute to a more effective immunological defense against HCC. Moreover, patients who achieved SVR with DAAs were found to have more HCVspecific $\mathrm{CD}^{+} \mathrm{T}$ cells post-treatment compared to patients who failed. Apart from the frequency of $\mathrm{HCV}$-specific $\mathrm{CD} 8^{+}$cells, the number of positive responses after $\mathrm{HCV}$-specific peptide stimulation increased in patients with SVR between baseline and follow-up week 24 [59]. These results, although based on a limited number of patients $(\mathrm{n}=51)$, imply that $\mathrm{CD} 8^{+} \mathrm{T}$-cell dysfunction caused by ongoing viral replication could be reversible shortly after DAA-induced HCV clearance.

To recapitulate, given the previous studies that correlated DAAs with higher HCC rates, it has been presumed that the fast-driven HCV clearance could provoke an abrupt cessation of antigen stimulation, causing a rapid imbalance in immune control and affecting HCC immunological surveillance, especially in cases of advanced liver disease or with previous HCC history. However, this mechanism is purely speculative and there are no robust published data to prove it. Although DAA treatment seems to have no significant impact on the
HCV-related increased number of Treg cells, even after SVR [56], it seems to restore NK and HCV-specific CD8 ${ }^{+}$T-cell function [57-59]. Therefore, the exact status of the complex immunological equilibrium following HCV clearance and its impact on HCC development need to be further studied before we can draw safe conclusions regarding the specific role of DAAs in hepatocarcinogenesis.

\section{Biomarkers}

So far, a novel diagnostic biomarker to detect early HCC does not exist. $\alpha$-Fetoprotein is no longer recommended by the American Association for the Study of Liver Diseases' guidelines for surveillance or diagnosis of HCC [60]. Molecules such as vascular endothelial growth factor (VEGF), angiopoietin-2 or c-Kit, micro-RNAs etc., have been used as predictors of outcome in patients with advanced hepatocellular carcinoma $[61,6]$. In a recent study it was shown that DAA administration induced an early increase in serum VEGF level, which returned to the pre-treatment levels after the end of therapy [63]. The possibility that this finding may represent a mechanism that could possibly lead to accelerated growth of undetected HCC after DAA administration still needs to be clarified. 


\section{Concluding remarks}

Recently, raised concern regarding an increased risk of either de novo development of HCC or HCC recurrence after treatment with DAAs has been under discussion. Questions have also been raised regarding the optimal timing of $\mathrm{HCV}$ treatment in patients with HCC. Importantly, most recent studies including large numbers of patients confirm that DAAinduced SVR decreases the risk of de novo occurrence of HCC, as expected after the elimination of HCV. However, patients with previous HCC should be carefully investigated to confirm complete HCC remission before starting, and close follow up should be performed after DAA treatment. Further research is certainly needed to elucidate the changes in the immunological milieu and affected cellular behavior after eradication of $\mathrm{HCV}$ infection with DAA treatment.

\section{References}

1. Calvaruso V, Petta S, Craxì A. Is global elimination of HCV realistic? Liver Int 2018;38(Suppl 1):40-46.

2. Walker AJ, Peacock CJ, Pedergnana V, Irving WL; STOP-HCV Consortium. Host genetic factors associated with hepatocellular carcinoma in patients with hepatitis $\mathrm{C}$ virus infection: a systematic review. J Viral Hepat 2018;25:442-456.

3. Dimitroulis D, Damaskos C, Valsami S, et al. From diagnosis to treatment of hepatocellular carcinoma: An epidemic problem for both developed and developing world. World J Gastroenterol 2017;23:5282-5294.

4. Beste LA, Ioannou GN. Prevalence and treatment of chronic hepatitis $\mathrm{C}$ virus infection in the US Department of Veterans Affairs. Epidemiol Rev 2015;37:131-143.

5. Zibbell JE, Asher AK, Patel RC, et al. Increases in acute hepatitis C virus infection related to a growing opioid epidemic and associated injection drug use, United States, 2004 to 2014. Am J Public Health 2018;108:175-181.

6. G. V. Papatheodoridis GV, Hatzakis A, Cholongitas E, et al. Hepatitis C: The beginning of the end-key elements for successful European and national strategies to eliminate HCV in Europe. $J$ Viral Hepat 2018;25(Suppl 1):6-17.

7. Starley BQ, Calcagno CJ, Harrison SA. Nonalcoholic fatty liver disease and hepatocellular carcinoma: a weighty connection. Hepatology 2010;51:1820-1832.

8. Sangiovanni A, Prati GM, Fasani P, et al. The natural history of compensated cirrhosis due to hepatitis C virus: A 17-year cohort study of 214 patients. Hepatology 2006;43:1303-1310.

9. Chang $\mathrm{KC}, \mathrm{Ye} \mathrm{YH}, \mathrm{Wu} \mathrm{CK}$, et al. Risk factors for development of hepatocellular carcinoma in patients with chronic hepatitis $\mathrm{C}$ without sustained response to combination therapy. J Formos Med Assoc 2017 [Epub ahead of print]. doi: 10.1016/j.jfma.2017.11.008

10. Velosa J, Serejo F, Marinho R, Nunes J, Glória H. Eradication of hepatitis $\mathrm{C}$ virus reduces the risk of hepatocellular carcinoma in patients with compensated cirrhosis. Dig Dis Sci2011;56:1853-1861.

11. Di Marco V, Calvaruso V, Ferraro D, et al. Effects of eradicating hepatitis $\mathrm{C}$ virus infection in patients with cirrhosis differ with stage of portal hypertension. Gastroenterology 2016;151:130-139.

12. Nishiguchi S, Kuroki T, Nakatani S, et al. Randomised trial of effects of interferon-alpha on incidence of hepatocellular carcinoma in chronic active hepatitis C with cirrhosis. Lancet 1995;346:1051-1055.
13. Lok AS, Everhart JE, Wright EC, et al. Maintenance peginterferon therapy and other factors associated with hepatocellular carcinoma in patients with advanced hepatitis C. Gastroenterology 2011;140:840-849.

14. Afdhal NH, Levine R, Brown R Jr, Freilich B, O’Brien M, Brass C. Colchicine versus peg-interferon alfa $2 \mathrm{~B}$ long term therapy: results of the 4 year copilot trial. J Hepatol 2008;48:S4.

15. Bruix J, Poynard T, Colombo M, et al. Pegintron maintenance therapy in cirrhotic (Metavir F4) HCV patients, who failed to respond to Interferon/Ribavirn (IR) therapy: final results of the EPIC3 cirrhosis maintenance trial. J Hepatol 2009;50:S22.

16. Bruix J, Poynard T, Colombo M, et al. EPIC3 Study Group. Maintenance therapy with peginterferon alfa-2b does not prevent hepatocellular carcinoma in cirrhotic patients with chronic hepatitis C. Gastroenterology 2011;140:1990-1999.

17. Aleman S, Rahbin N, Weiland O, et al. A risk for hepatocellular carcinoma persists long-term after sustained virologic response in patients with hepatitis C-associated liver cirrhosis. Clin Infect Dis 2013;57:230-236.

18. El-Serag HB, Kanwal F, Richardson P, Kramer J. Risk of hepatocellular carcinoma after sustained virological response in Veterans with hepatitis $\mathrm{C}$ virus infection. Hepatology 2016;64:130-137.

19. Toyoda H, Kumada T, Tada T, et al. Risk factors of hepatocellular carcinoma development in non-cirrhotic patients with sustained virologic response for chronic hepatitis $\mathrm{C}$ virus infection. $J$ Gastroenterol Hepatol 2015;30:1183-1189.

20. European Association for the Study of the Liver. Electronic address: easloffice@easloffice.eu. EASL Recommendations on treatment of hepatitis C 2016. J Hepatol 2017;66:153-194.

21. Conti F, Buonfiglioli F, Scuteri A, et al. Early occurrence and recurrence of hepatocellular carcinoma in $\mathrm{HCV}$-related cirrhosis treated with direct-acting antivirals. J Hepatol 2016;65:727-733.

22. Reig M, Mariño Z, Perelló C, et al. Unexpected high rate of early tumor recurrence in patients with $\mathrm{HCV}$-related HCC undergoing interferon-free therapy. J Hepatol 2016;65:719-726.

23. ANRS collaborative study group on hepatocellular carcinoma (ANRS CO22 HEPATHER, CO12 CirVir and CO23 CUPILT cohorts). Electronic address: stanislas.pol@aphp.fr. Lack of evidence of an effect of direct-acting antivirals on the recurrence of hepatocellular carcinoma: Data from three ANRS cohorts. $J$ Hepatol 2016;65:734-740.

24. Yang JD, Aqel BA, Pungpapong S, Gores GJ, Roberts LR, Leise MD. Direct acting antiviral therapy and tumor recurrence after liver transplantation for hepatitis C-associated hepatocellular carcinoma. J Hepatol 2016;65:859-860.

25. Rincón D, et al. Spanish Group for the Study of the Use of Directacting Drugs Hepatitis C Collaborating Group. Effectiveness, safety and clinical outcomes of direct-acting antiviral therapy in HCV genotype 1 infection: Results from a Spanish real-world cohort. $J$ Hepatol 2017;66:1138-1148.

26. Cabibbo G, Petta S, Calvaruso V, et al. Rete Sicilia Selezione Terapia - HCV (RESIST-HCV). Is early recurrence of hepatocellular carcinoma in HCV cirrhotic patients affected by treatment with direct-acting antivirals? A prospective multicentre study. Aliment Pharmacol Ther 2017;46:688-695.

27. Minami T, Tateishi R, Nakagomi R, et al. The impact of directacting antivirals on early tumor recurrence after radiofrequency ablation in hepatitis C-related hepatocellular carcinoma. J Hepatol 2016;65:1272-1273.

28. Ikeda K, Kawamura Y, Kobayashi M, et al. Direct-acting antivirals decreased tumor recurrence after initial treatment of hepatitis C virus-related hepatocellular carcinoma. Dig Dis Sci 2017;62:2932-2942.

29. Adhoute X, Penaranda G, Raoul JL, et al. Hepatocellular carcinoma 
recurrence in hepatitis $\mathrm{C}$ virus-related cirrhosis treated with directacting antivirals: a case-control study. Eur J Gastroenterol Hepatol 2018;30:368-375.

30. El Kassas M, Funk AL, Salaheldin M, et al. Increased recurrence rates of hepatocellular carcinoma after DAA therapy in a hepatitis C-infected Egyptian cohort: A comparative analysis. J Viral Hepat 2018;25:623-630.

31. Ravi S, Axley P, Jones D, et al. Unusually high rates of hepatocellular carcinoma after treatment with direct-acting antiviral therapy for hepatitis C related cirrhosis. Gastroenterology 2017;152:911-912.

32. Kanwal F, Kramer J, Asch SM, Chayanupatkul M, Cao Y, El-Serag HB. Risk of hepatocellular cancer in HCV patients treated with direct-acting antiviral agents. Gastroenterology 2017;153:996-1005.

33. Ioannou GN, Green KP, Berry K. HCV eradication induced by direct-acting antiviral agents reduces the risk of hepatocellular carcinoma. J Hepatol 2018;68:25-32.

34. Calvaruso V, Cabibbo G, Cacciola I, et al. Incidence of hepatocellular carcinoma in patients with $\mathrm{HCV}$-associated cirrhosis treated with direct-acting antiviral agents. Gastroenterology 2018 Apr 12 [Epub ahead of print]. doi: 10.1053/j.gastro.2018.04.008

35. Romano A, Angeli P, Piovesan S, et al. Newly diagnosed hepatocellular carcinoma in patients with advanced hepatitis C treated with DAAs: a prospective population study. J Hepatol 2018;69:345-352.

36. Li DK, Ren Y, Fierer DS, et al. The short-term incidence of hepatocellular carcinoma is not increased after hepatitis C treatment with direct-acting antivirals: an ERCHIVES study. Hepatology 2018;67:2244-2253.

37. Nagata $H$, Nakagawa $M$, Asahina $Y$, et al. Ochanomizu Liver Conference Study Group. Effect of interferon-based and -free therapy on early occurrence and recurrence of hepatocellular carcinoma in chronic hepatitis C. J Hepatol 2017;67:933-939.

38. Ogawa E, Furusyo N, Nomura H, et al. Kyushu University Liver Disease Study (KULDS) Group. Short-term risk of hepatocellular carcinoma after hepatitis $C$ virus eradication following direct-acting anti-viral treatment. Aliment Pharmacol Ther 2018;47:104-113.

39. Nagaoki $Y$, Imamura $M$, Aikata $H$, et al. The risks of hepatocellular carcinoma development after HCV eradication are similar between patients treated with peg-interferon plus ribavirin and directacting antiviral therapy. PLoS One 2017;12:e0182710.

40. Bruix J, Gores GJ, Mazzaferro V. Hepatocellular carcinoma: clinical frontiers and perspectives. Gut 2014;63:844-855.

41. Kozbial K, Moser S, Schwarzer R, et al. Unexpected high incidence of hepatocellular carcinoma in cirrhotic patients with sustained virologic response following interferon-free direct-acting antiviral treatment. J Hepatol 2016;65:856-858.

42. Barash H, Gross ER, Edrei Y, et al. Accelerated carcinogenesis following liver regeneration is associated with chronic inflammation-induced double-strand DNA breaks. Proc Natl Acad Sci U S A 2010;107:2207-2212.

43. Li S, Hong M, Tan HY, Wang N, Feng Y. Insights into the role and interdependence of oxidative stress and inflammation in liver diseases. Oxid Med Cell Longev 2016;2016:4234061.

44. Orci LA, Lacotte S, Oldani G, et al. Effect of ischaemic preconditioning on recurrence of hepatocellular carcinoma in an experimental model of liver steatosis. Br J Surg 2016;103:417-426.

45. Chung RT, Gale M Jr, Polyak SJ, Lemon SM, Liang TJ, Hoofnagle JH.
Mechanisms of action of interferon and ribavirin in chronic hepatitis C: Summary of a workshop. Hepatology 2008;47:306-320. 46. Wherry EJ, Blattman JN, Murali-Krishna K, van der Most R, Ahmed R. Viral persistence alters CD8 T-cell immunodominance and tissue distribution and results in distinct stages of functional impairment. J Virol 2003;77:4911-4927.

47. Jun, Wherry EJ. T cell exhaustion. Nat Immunol 2011;12:492-499.

48. Paley MA, Kroy DC, Odorizzi PM, et al. Progenitor and terminal subsets of CD8+ T cells cooperate to contain chronic viral infection. Science 2012;338:1220-1225.

49. Schietinger A, Greenberg PD. Tolerance and exhaustion: defining mechanisms of T cell dysfunction. Trends Immunol 2014;35:51-60.

50. Wherry EJ, Barber DL, Kaech SM, Blattman JN, Ahmed R. Antigenindependent memory CD8 T cells do not develop during chronic viral infection. Proc Natl Acad Sci U S A 2004;101:16004-16009.

51. Blackburn SD, Shin H, Haining WN, et al. Coregulation of CD8+ $\mathrm{T}$ cell exhaustion by multiple inhibitory receptors during chronic viral infection. Nat Immunol 2009;10:29-37.

52. Park SH, Rehermann B. Immune responses to HCV and other hepatitis viruses. Immunity 2014;40:13-24.

53. Hao C, Zhou Y, He Y, et al. Imbalance of regulatory $\mathrm{T}$ cells and $\mathrm{T}$ helper type 17 cells in patients with chronic hepatitis C. Immunology 2014;143:531-538.

54. Claassen MA, de K RJ, Janssen HL, Boonstra A. Retention of CD4+ CD25+ FoxP3+ regulatory T cells in the liver after therapy-induced hepatitis C virus eradication in humans. J Virol 2011;85:5323-5330.

55. Nault JC, Colombo M. Hepatocellular carcinoma and direct acting antiviral treatments: Controversy after the revolution. J Hepatol 2016;65:663-665.

56. Langhans B, Nischalke HD, Krämer B, et al. Increased peripheral $\mathrm{CD} 4(+)$ regulatory $\mathrm{T}$ cells persist after successful directacting antiviral treatment of chronic hepatitis C. I Hepatol 2017;66:888-896.

57. Serti E, Chepa-Lotrea X, Kim YJ, et al. Successful interferon-free therapy of chronic hepatitis $C$ virus infection normalizes natural killer cell function. Gastroenterology 2015;149:190-200.

58. Nakamura I, Furuichi Y, Sugimoto K. Restoration of natural killer cell activity by interferon-free direct-acting antiviral combination therapy in chronic hepatitis C patients. Hepatol Res 2018 May 6 [Epub ahead of print]. doi: 10.1111/hepr.13186

59. Martin B, Hennecke N, Lohmann V, et al. Restoration of HCVspecific CD8+ T cell function by interferon-free therapy. J Hepatol 2014;61:538-543.

60. Heimbach JK, Kulik LM, Finn RS, et al. AASLD guidelines for the treatment of hepatocellular carcinoma. Hepatology 2018;67:358-380.

61. Llovet JM, Peña CE, Lathia CD, Shan M, Meinhardt G, Bruix J; SHARP Investigators Study Group. Plasma biomarkers as predictors of outcome in patients with advanced hepatocellular carcinoma. Clin Cancer Res 2012;18:2290-2300.

62. Motawi TK, Shaker OG, El-Maraghy SA, Senousy MA. Serum MicroRNAs as potential biomarkers for early diagnosis of hepatitis C virus-related hepatocellular carcinoma in Egyptian patients. PLoS One 2015;10:e137706.

63. Villani R, Facciorusso A, Bellanti F, et al. DAAs rapidly reduce inflammation but increase serum VEGF level: a rationale for tumor risk during anti-HCV treatment. PLoS One 2016;11:e167934. 